\title{
Effect of serum interleukin-1 receptor antagonist level on survival of patients with non-small cell lung cancer
}

\author{
MURAT YIGIT $^{1}$, SERKAN DEĞIRMENCIOĞLU ${ }^{2}$, ERHAN UGURLU $^{3}$ and ARZU YAREN ${ }^{2}$ \\ ${ }^{1}$ Department of Internal Medicine; ${ }^{2}$ Fahri Goksin Oncology Center and ${ }^{3}$ Department of Thoracic Oncology, \\ Pamukkale University, Affiliated to Pamukkale University Hospital, Bagbasi, Denizli 20070, Turkey
}

Received October 14, 2016; Accepted January 30, 2017

DOI: $10.3892 / \mathrm{mco} .2017 .1195$

\begin{abstract}
Due to poor prognosis in advanced non-small cell lung cancer (NSCLC), new effective markers are required in the monitoring of the disease. The present study aimed to investigate the association between the serum IL-1 receptor antagonist (IL-1Ra) level, overall survival (OS), and treatment response in NSCLC, and to evaluate the usefulness of the serum IL-1Ra level as a prognostic marker for NSCLC. Eighty patients (72 men and 8 women) and 40 healthy volunteers (13 men and 27 women) were included in the present study. The median progression-free survival was 16 weeks for patients with high serum IL-1Ra levels, and 35 weeks for patients with low serum IL-1Ra levels $(\mathrm{P}=0.027)$. The median OS was 38 weeks in patients with a high serum IL-1Ra level, and 62 weeks in patients with a low serum IL-1Ra level $(\mathrm{P}=0.065)$. The results of the present study have demonstrated that there was a significant correlation between IL-1Ra levels and NSCLC progression and survival, although the correlation between IL-1Ra levels and the response to treatment was not statistically significant. Therefore, the pre-treatment IL-1Ra level has been identified as a putative prognostic factor for NSCLC.
\end{abstract}

\section{Introduction}

Lung cancer was the leading cause of cancer-associated death in the US in 2015. An estimated 221,000 new cases of lung cancer were diagnosed, and 158,000 cancer-associated mortalities were recorded (1). Although smoking (90\%) represents the highest risk factor for lung cancer (2), only $10-15 \%$ of smokers are diagnosed with lung cancer, which indicates that other environmental factors, including asbestos, chromium, nickel, beryllium, arsenic, silica, cadmium, radon, chronic

Correspondence to: Dr Serkan Değirmencioğlu, Fahri Goksin Oncology Center, Pamukkale University, Affiliated to Pamukkale University Hospital, 11 University Street, Bagbasi, Denizli 20070, Turkey

E-mail: sdegirmencioglu@pau.edu.tr; drserkandeg@hotmail.com

Key words: non-small cell lung cancer, serum interleukin-1 receptor antagonist level, overall survival, treatment response obstructive pulmonary disease, and genetic factors also serve a key role in the etiology of the disease (3).

The American Joint Committee on Cancer (AJCC) clinical staging system is the most widely accepted tool in the evaluation of prognosis and survival of lung cancer (4). Serum albumin, C-reactive protein (CRP), hemoglobin, lactate dehydrogenase (LDH), the leukocyte count, interleukin (IL)-6, and tumor necrosis factor- $\alpha$ (TNF- $\alpha$ ) levels have been also shown to serve a predictive role (5). Furthermore, epidermal growth factor receptor, anaplastic lymphoma kinase, proto-oncogene tyrosine-protein kinase and Kirsten rat sarcoma 2 viral oncogene homolog mutational analyses have gained in importance in recent years, as they are helpful in terms of planning the treatment (6).

In addition, IL-1 is a versatile cytokine, which has unique physiological roles, including cytokine secretion in autoimmune diseases, vascular permeability, and induction of fever in sepsis (7). Previous studies have revealed that increased IL-1 secretion enhances the expression of genes that encode proteins involved in metastasis [i.e., matrix metalloproteinases (MMPs)], and secretion of growth and angiogenic factors, including vascular endothelial growth factor (VEGF), IL-8, IL-6, TNF- $\alpha$ and transforming growth factor- $\beta(8,9)$. Furthermore, IL-1 receptor antagonist (IL-1Ra) is a member of the IL-1 family, having homology with IL-1 $\alpha$ and IL-1 $\beta$ (10). IL-1Ra binds to IL- 1 receptors in a competitive manner without exerting biological activity. It is naturally produced, and competitively inhibits IL-1RI in T-lymphocytes and fibroblasts (11). Due to its ability to inhibit collagenase and prostaglandin synthesis, the recombinant version of IL-1Ra, anakinra, has been developed for the treatment of rheumatoid arthritis. Anakinra is able to reverse the IL-1-dependent effects (11). IL-1 induces tumor growth and metastasis (12), whereas, by contrast, IL-1Ra inhibits IL- $1 \alpha$ and IL- 6 secretion in cancer cells. The use of anakinra for the treatment of rheumatoid arthritis has revealed that the drug is well absorbed, with a safe side-effect profile, which makes it a good candidate for the treatment of cancer types caused by inflammation. Therefore, a number of studies have been performed to investigate whether IL-1Ra inhibits the effects of IL-1 and is effective as a treatment of choice in cancer therapy $(8,12)$. These studies have demonstrated that IL-1Ra suppresses metastasis and tumor proliferation, thereby inhibiting synthesis of angiogenic factors, such as VEGF and IL-8 (12). 
The present study aimed to investigate the possible association between the serum IL-1Ra level, overall survival (OS), and treatment response in advanced non-small cell lung cancer (NSCLC), and to evaluate the usefulness of the serum IL-1Ra level as a prognostic marker for NSCLC.

\section{Patients and methods}

A total of 80 chemotherapy-naive patients who were admitted to the Department of Medical Oncology, Pamukkale University, Denizli, Turkey for the first time and who were diagnosed with NSCLC following a pathological examination were included. Written informed consent was obtained from each patient. The study protocol was approved by the Ethics Committee of Pamukkale University, Faculty of Medicine, Clinical Research (dated 20.09.2010/05). The present study was conducted in accordance with the principles of the Declaration of Helsinki. Only patients with an advanced disease (stage IIIB or stage IV) with a Performance Status (PS) of 0,1 , and 2, according to the World Health Organization (WHO), were enrolled. Exclusion criteria were as follows: a PS of $\leq 3$ at the time of admission; brain metastasis or suspected brain metastasis; age $>80$ years; and early-stage disease (stage I, II, or IIIA). The control group consisted of 40 healthy individuals aged between 50 and 71 years, who did not use any medication and who did not have any known diseases.

Statistical analysis. Statistical analysis was performed using SPSS version 16.0 software (SPSS Inc., Chicago, IL, USA). A cut-off value for IL-1Ra was calculated as $10 \mathrm{ng} / \mathrm{ml}$. Values that were equal to or lower than the cut-off value were considered low, whereas values exceeding the cut-off value were considered high. The chi-square and Mann-Whitney $\mathrm{U}$ tests were used to compare the characteristics of the patients with NSCLC and healthy controls. The Spearman and Pearson's correlation tests were used for the correlation analysis. Kaplan-Meier survival plot analysis was used to calculate OS, progression-free survival (PFS), and survival curves. Cox regression analysis was used to determine the factors affecting the survival of patients and progression of the disease. A confidence interval of $95 \%$ was used. $\mathrm{P}<0.05$ was considered to indicate a statistically significant difference.

\section{Results}

Demographic and clinical characteristics of the patients and controls are shown in Table I.

Survival was shorter in patients with high serum IL-1Ra levels (38 weeks), compared with the patients with low serum IL-1Ra levels (62 weeks; $\mathrm{P}=0.065$ ). In addition, serum IL-1Ra levels had an impact on progression. The time until progression was significantly shorter in patients with high serum IL-1Ra levels (16 weeks) compared with the patients with low serum IL-1Ra levels (35 weeks; $\mathrm{P}=0.027$ ).

Cox regression analysis revealed that albumin and ferritin levels had a significant impact on progression $(\mathrm{P}=0.042$ and $\mathrm{P}=0.001$, respectively). The Cox regression analysis for PFS is shown in Table II.
Multivariate analysis showed that the albumin level, the elevated CRP level, and the level of IL-1Ra had an impact on OS ( $\mathrm{P}=0.019,0.05$ and 0.04, respectively). Low albumin levels were associated with a 3 -fold decrease in OS, whereas high CRP levels were associated with a 2.9-fold decrease in OS. High serum levels of IL-1Ra were associated with a 2.2-fold decrease in OS. Cox regression analysis for OS is shown in Table III.

The serum levels of IL-1Ra exhibited an inverse correlation with the median PFS. The median PFS was 16 weeks (95\% CI: 12-19 weeks) for patients with high serum IL-1Ra levels, and 35 weeks for patients with low serum IL-1Ra levels (95\% CI: 12-57 weeks; P=0.027) (Fig. 1).

High serum levels of IL-1Ra were associated with a decreased median OS. Accordingly, the median OS was 38 weeks (95\% CI: 26.05-49.94) in patients with a high serum IL-1Ra level, and 62 weeks (95\% CI: 40.0-83.9) in patients with a low serum IL-1Ra level $(\mathrm{P}=0.065)$ (Fig. 2).

\section{Discussion}

IL-1, which is a versatile cytokine, exerts a key role not only in physiological processes, but also in pathological processes, such as those concerned with autoimmune diseases, sepsis, and malignancies (12). The IL-1 family consists of proinflammatory and immunoregulatory cytokines, including IL-1 $\alpha$, IL-1 $\beta$ and IL-1Ra (13). IL-1 $\alpha$ and IL-1- $\beta$ act as agonists, whereas IL-1Ra has antagonistic effects. Although IL-1 $\alpha$ and IL-1- $\beta$ are encoded on different genes, they bind to the identical receptor with similar functions (11). Despite sharing the same biological function, however, IL-1 $\alpha$ is localized in the cytoplasm or cell membrane and serves a key role in intracellular regulation (11). By contrast, IL-1 $\beta$ is first processed by IL- $1 \beta$ converting enzyme, and the resulting mature form is subsequently secreted. The increase in IL-1 $\beta$ concentration in case of an infection or inflammation, rather than of IL-1 $\alpha$, suggests that IL-1 $\beta$ exerts systemic effects (11).

IL-1Ra inhibits the inflammatory and tumor-activating properties of IL-1 (12). In vivo studies on mice revealed that IL-1Ra suppresses angiogenesis, tumor growth, and metastasis (13). IL-1Ra levels are also raised in autoimmune disorders in which the levels of IL-1 are increased, such as metabolic diseases, sepsis, and cancer; therefore, the IL-1Ra level may be used as an indicator of IL-1 activity (12).

Previous studies on IL-1 have demonstrated that IL-1 acts as a tumor growth factor, and increases proliferation of tumor cells (11). In addition, IL-1 is known to induce metastasisinducing molecules (e.g., MMPs) and angiogenic molecules (e.g., VEGF) (8). Angiogenesis serves a key role in tumorassociated inflammation, tumor growth, and metastasis.

The protein expression of IL-1Ra in lung cancer tissues is markedly higher compared with that of normal lung tissue (14). This finding is interpreted as an 'escape mechanism' from host defense systems.

In the present study, it has been shown that the levels of serum IL-1Ra were higher in patients with NSCLC compared with the control subjects; however, the difference between the groups was not statistically significant. Similarly to our results, a previous study revealed that IL-1Ra levels were higher in patients with thyroid cancer (15). In normal cells, 
Table I. Demographic and clinical features of patients with non-small cell lung cancer and control subjects.

\begin{tabular}{|c|c|c|c|}
\hline Feature & Patients $(n=80)$ & Controls $(n=40)$ & P-value \\
\hline Age (years) & $64.1 \pm 8.9$ & $59.5 \pm 5.6$ & 0.41 \\
\hline Gender (male/female) & $72 / 8$ & $13 / 27$ & $<0.001^{\mathrm{a}}$ \\
\hline Hemoglobin (g/dl) & $12.61 \pm 1.7$ & $13.61 \pm 1.34$ & $0.030^{\mathrm{a}}$ \\
\hline $\mathrm{WBC}(\mathrm{K} / \mu \mathrm{l})$ & $11,342 \pm 6,634$ & $7,033 \pm 1,742$ & $<0.001^{\mathrm{a}}$ \\
\hline PNLs $(\mathrm{K} / \mu \mathrm{l})$ & $8,011 \pm 6,366$ & $4,008 \pm 1,322$ & $<0.001^{\mathrm{a}}$ \\
\hline $\operatorname{PLTs}(\mathrm{K} / \mu \mathrm{l})$ & $365,742 \pm 139,623$ & $247,000 \pm 52,728$ & $<0.001^{\mathrm{a}}$ \\
\hline Albumin (g/dl) & $4.02 \pm 0.49$ & $4.45 \pm 0.33$ & $<0.001^{\mathrm{a}}$ \\
\hline $\mathrm{CRP}(\mathrm{mg} / \mathrm{dl})$ & $6.55 \pm 7.03$ & $0.36 \pm 0.65$ & $<0.001^{\mathrm{a}}$ \\
\hline LDH (U/l) & $282 \pm 29.02$ & $188 \pm 7.7$ & $0.008^{\mathrm{a}}$ \\
\hline Ferritin (ng/ml) & $398.76 \pm 78.7$ & $63.4 \pm 10.03$ & $<0.001^{\mathrm{a}}$ \\
\hline IL-1Ra & $8.85 \pm 4.99$ & $8.07 \pm 5.13$ & 0.542 \\
\hline \multicolumn{4}{|l|}{ Clinical features of patients (\%) } \\
\hline Adenocarcinoma & $16(20)$ & & \\
\hline Squamous-cell carcinoma & $54(67.5)$ & & \\
\hline Other histological subtypes & $10(12.5)$ & & \\
\hline Smokers & $72(90)$ & & \\
\hline Experienced weight loss at diagnosis & $44(55)$ & & \\
\hline
\end{tabular}

Results are shown as the mean \pm standard deviation. ${ }^{\mathrm{a}} \mathrm{P}<0.05$ indicated a statistically significant difference with respect to the control. CRP, C-reactive protein; IL-1Ra, interleukin-1 receptor antagonist; LDH, lactate dehydrogenase; PNL, polymorphonucleocyte; PLT, platelet; WBC, white blood count.

Table II. Cox regression analysis to determine factors affecting progression-free survival.

\begin{tabular}{lccc}
\hline & $\operatorname{Exp}(\mathrm{B})$ & P-value & $95 \% \mathrm{CI}$ \\
\hline Albumin & 0.557 & $0.042^{\mathrm{a}}$ & $0.317-0.978$ \\
Ferritin & 1.001 & $0.001^{\mathrm{a}}$ & $1.000-1.001$ \\
\hline
\end{tabular}

${ }^{\mathrm{a}} \mathrm{P}<0.05$ was considered to indicate a statistically significant difference. $\mathrm{CI}$, confidence interval; $\operatorname{Exp}(\mathrm{B})$, exponentiated logistic coefficient.

Table III. Cox regression analysis for overall survival.

\begin{tabular}{lccc}
\hline & $\operatorname{Exp}(\mathrm{B})$ & P-value & $95 \% \mathrm{CI}$ \\
\hline Albumin & 3.034 & $0.019^{\mathrm{a}}$ & $1.326-6.941$ \\
CRP & 2.908 & $0.05^{\mathrm{a}}$ & $1.279-6.613$ \\
IL-1Ra & 2.284 & $0.04^{\mathrm{a}}$ & $1.279-4.079$
\end{tabular}

${ }^{a} \mathrm{P}<0.05$ was considered to indicate a statistically significant difference. $\mathrm{CI}$, confidence interval; $\operatorname{Exp}(\mathrm{B})$, exponentiated logistic coefficient; CRP, C-reactive protein; IL-1Ra, interleukin-1 receptor antagonist.

IL-1 secretion is mediated via inflammatory stimulation or cytokines, whereas tumor cells synthesize and secrete IL-1 through an autocrine mechanism. In contrast with the situation in normal cells, tumor cells exhibit non-selective IL-1 secretion. IL-1 is rarely secreted from normal cells; however, it is continuously synthesized in different cancer cells (7). Inflammation is frequently investigated in the etiology of different cancer types, including thyroid cancer. The immune system is hyperactive in Hashimoto's thyroiditis, and an association between this disease and thyroid cancer has been reported (15).

In addition, a complex association exists between IL-1Ra and the severity of inflammation. Studies on different cancer types (including pancreatic cancer and breast cancer) have revealed that high levels of IL-1Ra are correlated with the severity of disease $(16,17)$. On the other hand, a negative correlation between IL-1Ra levels and disease severity was identified in the case of acute myeloid leukemia (17). These findings may be interpreted as follows: An increase in the serum levels of IL-1Ra is able to reduce the tumor-aggravating effects of IL-1; in this case, it is also able to decrease the severity of the disease. However, in certain cancer types, IL-1RA may fail to reduce these effects, and the tumor prognosis may consequently become worse, despite the presence of high serum IL-1Ra levels (17).

Danis et al (18) demonstrated that IL-1 receptor antagonist gene allele 2 (ILRN*2) polymorphism led to increased levels of IL-1Ra and a decrease in IL-1 $\alpha$ synthesis. High IL-1Ra levels and inflammation are considered to decrease the removal of carcinogenic polycyclic hydrocarbons, which are taken into the body following exposure to smoking. Hu et al (19) suggested that the ILRN*2 polymorphism was associated with a decreased risk of lung cancer. This functional polymorphism affects serum IL-1Ra levels and exerts a role in the immune 


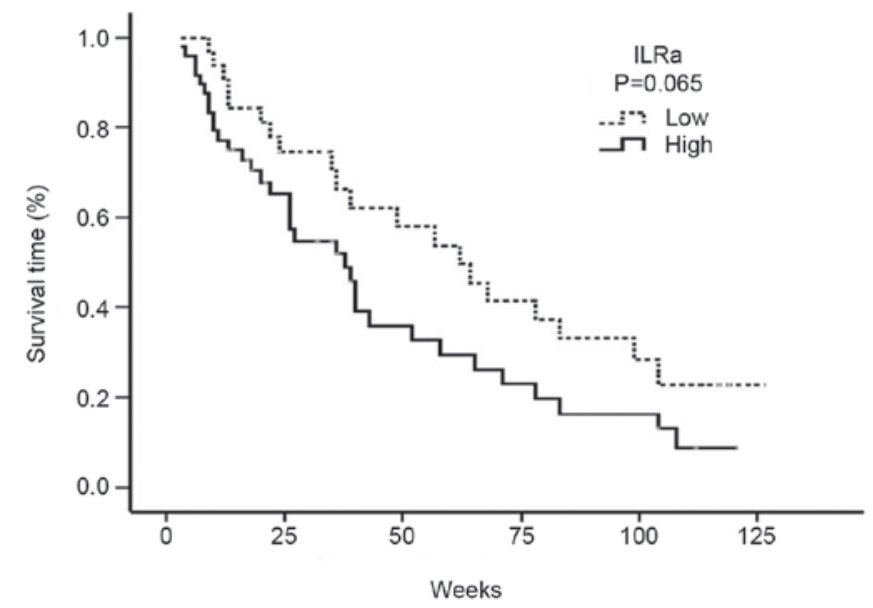

Figure 1. Progression-free survival curve analysis of the serum IL-1Ra levels. ILRa, interleukin-1 receptor antagonist.

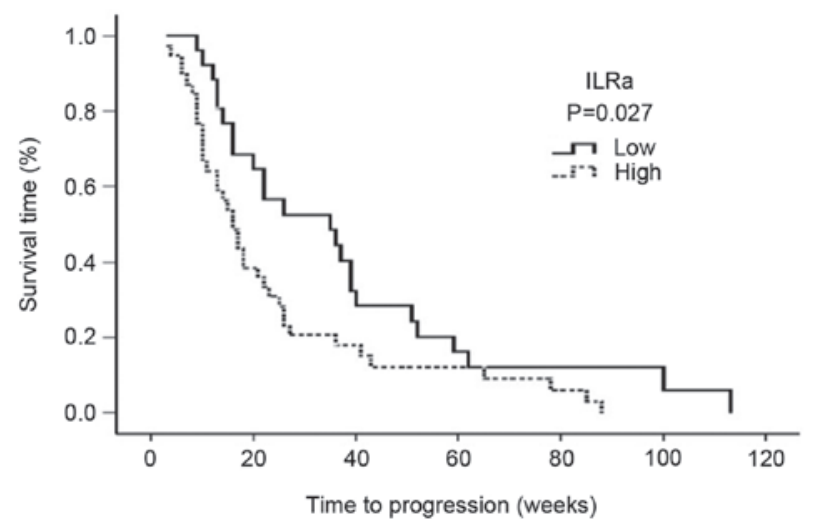

Figure 2. Overall survival curve analysis of the serum IL-1Ra levels. ILRa, interleukin-1 receptor antagonist.

response and in cancer risk. In a previous study, the effect of polymorphism on cancer risk was compared between patients with a lung cancer diagnosis and healthy control subjects. The presence of this polymorphism was associated with a $32 \%$ decrease in the risk of lung cancer, and, in particular, a $47 \%$ decrease was observed in the non-smoking group (19). A subsequent study revealed that the IL-1Ra gene polymorphism alone did not increase cancer risk, but that the cancer risk was increased when the IL-1 $\beta$ gene polymorphism was also present (20). According to a Norwegian study, carrying a homozygous ILRN*1 allele and the IL-1B-31T allele together increases the risk of NSCLC by 3.08-fold (21).

McKeown et al (22) compared serum levels of IL-1RA and other inflammatory cytokines between patients with NSCLC and healthy control subjects. These authors demonstrated that the serum levels of IL6, IL8, CRP, and IL-1Ra were significantly higher in the NSCLC group compared with the control group (22). In addition, these authors also identified a significant correlation between serum IL- 6 and IL-1Ra levels, and serum CRP levels. These findings suggested that, in addition to the serum level of CRP, the serum level of IL-1Ra may also serve as a prognostic marker for NSCLC.

In a comparative study, 68 inflammation markers in the circulation were analyzed among patients with lung cancer, who were enrolled in a follow-up study along with patients with prostate cancer, colorectal cancer, ovarian cancer, and healthy control subjects (2). Among these parameters, high levels of serum IL-1Ra were associated with a $29 \%$ decreased risk of lung cancer. Subgroup analyses revealed no significant differences existed between individuals who had never smoked $(\mathrm{P}=0.25)$ and those who were active smokers $(\mathrm{P}=0.71)$, whereas a significant difference was observed in ex-smokers $(\mathrm{P}<0.001)$. In that study, serum samples were collected 2.9 years (median) prior to the diagnosis of lung cancer. Therefore, monitoring the serum IL-1Ra levels in individuals who are at risk of lung cancer (e.g. smokers, and sufferers of pulmonary fibrosis, chronic obstructive pulmonary disease, and chronic pulmonary infections) may be useful for an early diagnosis of lung cancer.

Furthermore, previous studies on IL-1Ra have revealed that tissue levels of IL-1Ra/IL-1 $\beta$ are negatively correlated with VEGF in patients with colorectal cancer, and IL-1Ra inhibits VEGF and reduces invasion (7). As VEGF enhances angiogenesis, and leads to a poor tumor prognosis, anti-VEGF antibodies (e.g., bevacizumab) are used for the treatment of lung cancer. Infusion treatment with an IL-1Ra analog (anakinra) is used for patients with rheumatoid arthritis, and this has a safe side-effect profile. The combination of agents which inhibit the effects of IL-1 and reduce the VEGF secretion (e.g., anakinra) with bevacizumab may also lead to an increase in treatment efficacy, leading to reduced toxicity due to lower doses (7).

In a further study, Herfs et al (23) exposed the rats to cigarette smoke for $16 \mathrm{~h}$, and demonstrated that treatment with anakinra led to a marked reduction in epithelial hyperplasia, and eliminated the development of squamous metaplasia, which is a pre-malignant lesion. Thus, the authors suggested that anti-IL-1Ra treatment for chronic obstructive pulmonary disease may serve a useful role in prevention of lung cancer through epithelial remodeling (23).

Previous studies on patients with estrogen receptornegative (ER-) breast cancer have demonstrated that IL-1Ra negativity is a prognostic factor. Angiogenesis is a critical process for breast cancer growth, and VEGF is able to induce angiogenesis and accelerate tumor growth, thereby leading to a poor prognosis. IL-1 enhances angiogenesis by inducing VEGF expression (17). It appears that the expression level of IL-1Ra increases when IL-1 levels are high; however, this increase is not sufficient to inhibit the effects of IL-1 in breast cancer.

In the study, PFS and OS were shorter in patients with a level of high IL-1Ra, suggesting the presence of severe inflammation in these patients. On the other hand, the high IL-1Ra levels did not appear to serve any protective roles.

In conclusion, the present study has demonstrated that there was a correlation between the levels of IL-1Ra and NSCLC progression and survival, although the correlation between IL-1Ra levels and the response to treatment was not statistically significant. Given the safe side-effect profile of IL-1Ra-associated drugs, and the importance of IL-1 in cancer, the use of such drugs for cancer treatment appears to afford a feasible approach. However, additional, well-designed, large-scale studies are required to investigate the potential of IL-1Ra for cancer treatment. 


\section{References}

1. Siegel RL, Miller KD and Jemal A: Cancer statistics, 2015. CA Cancer J Clin 65: 5-29, 2015.

2. Shiels MS, Pfeiffer RM, Hildesheim A, Engels EA, Kemp TJ, Park JH, Katki HA, Koshiol J, Shelton G, Caporaso NE, et al: Circulating inflammation markers and prospective risk for lung cancer. J Natl Cancer Inst 105: 1871-1880, 2013.

3. Straif K, Benbrahim-Tallaa L, Baan R, Grosse Y, Secretan B, El Ghissassi F, Bouvard V, Guha N, Freeman C, Galichet L, et al; WHO International Agency for Research on Cancer Monograph Working Group: A review of human carcinogens--Part C: Metals, arsenic, dusts, and fibres. Lancet Oncol 10: 453-454, 2009.

4. Edge SB, Byrd DR, Compton CC, et al: AJCC Cancer Staging Manual. 7th edition. Springer, New York, 2010.

5. Yotsukura M, Ohtsuka T, Kaseda K, Kamiyama I, Hayashi Y and Asamura H: Value of the Glasgow Prognostic Score as a Prognostic Factor in Resectable Non-Small Cell Lung Cancer. J Thorac Oncol 11: 1311-1318, 2016.

6. Sholl LM, Aisner DL, Varella-Garcia M, Berry LD, DiasSantagata D, Wistuba II, Chen H, Fujimoto J, Kugler K, Franklin WA, et al; LCMC Investigators: Multi-institutional Oncogenic Driver Mutation Analysis in Lung Adenocarcinoma: The Lung Cancer Mutation Consortium Experience. J Thorac Oncol 10: 768-777, 2015.

7. Dinarello CA: Biologic basis for interleukin-1 in disease. Blood 87: 2095-2147, 1996.

8. Konishi N, Miki C, Yoshida T, Tanaka K, Toiyama Y and Kusunoki M: Interleukin-1 receptor antagonist inhibits the expression of vascular endothelial growth factor in colorectal carcinoma. Oncology 68: 138-145, 2005.

9. Barillé S, Akhoundi C, Collette M, Mellerin MP, Rapp MJ, Harousseau JL, Bataille R and Amiot M: Metalloproteinases in multiple myeloma: Production of matrix metalloproteinase- 9 (MMP-9), activation of proMMP-2, and induction of MMP-1 by myeloma cells. Blood 90: 1649-1655, 1997.

10. Apte RN and Voronov E: Interleukin-1--a major pleiotropic cytokine in tumor-host interactions. Semin Cancer Biol 12: 277-290, 2002

11. Dinarello CA: Interleukin-1 and interleukin-1 antagonism. Blood 77: 1627-1652, 1991

12. Lewis AM, Varghese $\mathrm{S}, \mathrm{Xu} \mathrm{H}$ and Alexander HR: Interleukin-1 and cancer progression: The emerging role of interleukin-1 receptor antagonist as a novel therapeutic agent in cancer treatment. J Transl Med 4: 48, 2006.

13. Voronov E, Carmi Y and Apte RN: Role of IL-1-mediated inflammation in tumor angiogenesis. Adv Exp Med Biol 601: 265-270, 2007
14. Smith DR, Kunkel SL, Standiford TJ, Chensue SW, Rolfe MW, Orringer MB, Whyte RI, Burdick MD, Danforth JM, Gilbert AR, et al: The production of interleukin-1 receptor antagonist by human bronchogenic carcinoma. Am J Pathol 143: 794-803, 1993.

15. Fuksiewicz M, Kaminska J, Kotowicz B, Kowalska M, Rubach M and Pienkowski T: Serum cytokine levels and the expression of estrogen and progesterone receptors in breast cancer patients. Clin Chem Lab Med 44: 1092-1097, 2006.

16. Barber MD, Ross JA and Fearon KC: Changes in nutritional, functional, and inflammatory markers in advanced pancreatic cancer. Nutr Cancer 35: 106-110, 1999.

17. Bruserud O, Aasen I, Akselsen PE, Bergheim J, Rasmussen G and Nesthus I: Interleukin 1 receptor antagonist (IL1RA) in acute leukaemia: IL1RA is both secreted spontaneously by myelogenous leukaemia blasts and is a part of the acute phase reaction in patients with chemotherapy-induced leucopenia. Eur J Haematol 57: 87-95, 1996.

18. Danis VA, Millington M, Hyland VJ and Grennan D: Cytokine production by normal human monocytes: Inter-subject variation and relationship to an IL-1 receptor antagonist (IL-1Ra) gene polymorphism. Clin Exp Immunol 99: 303-310, 1995.

19. Hu Z, Shao M, Chen Y, Zhou J, Qian J, Xu L, Ma H, Wang X, $\mathrm{Xu} Y, \mathrm{Lu} \mathrm{D}$, et al: Allele 2 of the interleukin-1 receptor antagonist gene (IL1RN*2) is associated with a decreased risk of primary lung cancer. Cancer Lett 236: 269-275, 2006.

20. Hurme M and Santtila S: IL-1 receptor antagonist (IL-1Ra) plasma levels are co-ordinately regulated by both IL-1Ra and IL-1 $\beta$ genes. Eur J Immunol 28: 2598-2602, 1998.

21. Lind H, Zienolddiny S, Ryberg D, Skaug V, Phillips DH and Haugen A: Interleukin 1 receptor antagonist gene polymorphism and risk of lung cancer: A possible interaction with polymorphisms in the interleukin 1 beta gene. Lung Cancer 50: 285-290, 2005.

22. McKeown DJ, Brown DJ, Kelly A, Wallace AM and McMillan DC: The relationship between circulating concentrations of C-reactive protein, inflammatory cytokines and cytokine receptors in patients with non-small-cell lung cancer. Br J Cancer 91: 1993-1995, 2004.

23. Herfs M, Hubert P, Poirrier AL, Vandevenne P, Renoux V, Habraken Y, Cataldo D, Boniver J and Delvenne P: Proinflammatory cytokines induce bronchial hyperplasia and squamous metaplasia in smokers: Implications for chronic obstructive pulmonary disease therapy. Am J Respir Cell Mol Biol 47: 67-79, 2012 